Atmos. Chem. Phys., 13, 3237-3243, 2013

www.atmos-chem-phys.net/13/3237/2013/

doi:10.5194/acp-13-3237-2013

(c) Author(s) 2013. CC Attribution 3.0 License.

\title{
Semi-empirical models for chlorine activation and ozone depletion in the Antarctic stratosphere: proof of concept
}

\author{
P. E. Huck ${ }^{1}$, G. E. Bodeker ${ }^{1}$, S. Kremser ${ }^{1}$, A. J. McDonald ${ }^{2}$, M. $\operatorname{Rex}^{3}$, and H. Struthers ${ }^{4,5}$ \\ ${ }^{1}$ Bodeker Scientific, Alexandra, New Zealand \\ ${ }^{2}$ Department of Physics and Astronomy, University of Canterbury, Christchurch, New Zealand \\ ${ }^{3}$ Alfred Wegener Institute, Potsdam, Germany \\ ${ }^{4}$ Department of Applied Environmental Science, Stockholm University, 10691, Stockholm, Sweden \\ ${ }^{5}$ Department of Meteorology, Stockholm University, 10691, Stockholm, Sweden
}

Correspondence to: P. E. Huck (petra@bodekerscientific.com)

Received: 4 September 2012 - Published in Atmos. Chem. Phys. Discuss.: 30 October 2012

Revised: 24 February 2013 - Accepted: 6 March 2013 - Published: 19 March 2013

\begin{abstract}
Two semi-empirical models were developed for the Antarctic stratosphere to relate the shift of species within total chlorine $\left(\mathrm{Cl}_{\mathrm{y}}=\mathrm{HCl}+\mathrm{ClONO}_{2}+\mathrm{HOCl}+2 \times \mathrm{Cl}_{2}+\right.$ $2 \times \mathrm{Cl}_{2} \mathrm{O}_{2}+\mathrm{ClO}+\mathrm{Cl}$ ) into the active forms (here: $\mathrm{ClO}_{\mathrm{x}}=$ $2 \times \mathrm{Cl}_{2} \mathrm{O}_{2}+\mathrm{ClO}$ ), and to relate the rate of ozone destruction to $\mathrm{ClO}_{\mathrm{x}}$. These two models provide a fast and computationally inexpensive way to describe the inter- and intraannual evolution of $\mathrm{ClO}_{\mathrm{x}}$ and ozone mass deficit (OMD) in the Antarctic spring. The models are based on the underlying physics/chemistry of the system and capture the key chemical and physical processes in the Antarctic stratosphere that determine the interaction between climate change and Antarctic ozone depletion. They were developed considering bulk effects of chemical mechanisms for the duration of the Antarctic vortex period and quantities averaged over the vortex area. The model equations were regressed against observations of daytime $\mathrm{ClO}$ and OMD providing a set of empirical fit coefficients. Both semi-empirical models are able to explain much of the intra- and inter-annual variability observed in daily $\mathrm{ClO}_{\mathrm{x}}$ and OMD time series. This proof-ofconcept paper outlines the semi-empirical approach to describing the evolution of Antarctic chlorine activation and ozone depletion.
\end{abstract}

\section{Introduction}

International best practice for projecting the evolution of the global ozone layer is to use chemistry-climate models (CCMs). However, modelling and predicting the ozone evolution with CCMs still shows large discrepancies in model-to-model and/or model-to-observation intercomparisons. Three sources of uncertainty contributing to the overall uncertainty in ozone projections were identified by CharltonPerez et al. (2010): (1) model uncertainty due to differences in the formulation of CCMs and inaccurate representations of dynamical and/or chemical processes, (2) internal variability and (3) uncertainty in future emissions of greenhouse gases (GHGs) and ozone depleting substances. CharltonPerez et al. (2010) indicate that the model uncertainty and uncertainties arising from future emissions scenarios are the dominant contributors to the overall uncertainty in the projections of future ozone abundances. Furthermore, one of the recommendations of SPARC CCMVal (2010) is that the simulation of the Antarctic ozone hole needs improvement in most CCMs. Many CCMs cannot represent the Antarctic ozone hole area and depth due to large ozone biases and nonrepresentative polar vortices. Ideally, projections should be based on an ensemble of model simulations that encompass the full range of uncertainty. However, due to their complexity, CCMs are very computationally demanding and expensive to run. 
In the past, alternative fast stratospheric chemistry schemes such as the Cariolle (Cariolle and Teyssèdre, 2007) and Linoz (McLinden et al., 2000; Hsu and Prather, 2009) schemes were used as simple chemistry schemes. Those schemes are linear parameterizations (first-order Taylor expansions) of ozone photochemistry as a function of local ozone, temperature and overhead column ozone. They provide seasonally varying global ozone fields for chemistry transport models or global climate models. However, both of these schemes are statistical rather than being based on the underlying physical processes, and are unlikely to be representative outside of the dataset on which they were trained. Therefore there is a need for an alternative approach as a quick pathfinder for more detailed CCM studies that can be used to conduct inexpensive projections of ozone based on physical and chemical processes.

Inter- and intra-annual variability in Antarctic ozone depletion is at root governed by meteorology and regulated by the interaction of gas-phase and heterogeneous chemistry, transport and dynamics. In this study a model with a simple realisation of the physical processes describing chlorine activation and ozone depletion over Antarctica was developed. Only bulk quantities were considered, and the seasonal evolution is summarised in simplified source and sink terms. A priori knowledge of stratospheric temperature fields and total inorganic stratospheric chlorine $\left(\mathrm{Cl}_{\mathrm{y}}\right)$ is required to conduct model projections. The processes considered for both semi-empirical models include the following: the Antarctic stratospheric polar vortex starts to spin up in April, and polar stratospheric clouds (PSCs) typically form in early to midMay. Heterogeneous reactions on PSC surfaces lead to the conversion of reservoir forms of chlorine into active forms (Solomon, 1999, and references therein). Once reactive chlorine is exposed to sunlight, chlorine-catalysed ozone destruction begins; sunlight also increases temperature, causing PSCs to sublimate, and increases chlorine deactivation rates. Furthermore, ozone production due to Chapman chemistry (Chapman, 1930) is ongoing as long as sunlight is available (Grooß et al., 2011). The final warming event usually occurs by December, and the polar vortex breaks apart (Waugh and Randel, 1999).

In addition to ozone destruction due to chlorine, bromine chemistry must be considered (WMO, 2011). On a per atom basis, bromine is much more efficient in destroying ozone than chlorine (e.g. Sinnhuber et al., 2009). However, the largest contribution to ozone depletion in the Antarctic stratosphere is due to the $\mathrm{ClO}+\mathrm{ClO}$ and $\mathrm{ClO}+\mathrm{BrO}$ cycles. In the absence of reactive chlorine, bromine would be inefficient in destroying ozone (Chipperfield and Pyle, 1998). Bromine reservoirs are also less stable than chlorine reservoirs, and conversion of the reservoir species to reactive forms is less dependent on heterogeneous chemistry. In summary, while chlorine is the primary driver of Antarctic ozone destruction, the seasonal evolution of $\mathrm{ClO}$ provides a good estimate of the ozone destroying potential (WMO, 2003), and bromine can be considered as an amplifying factor (von Hobe et al., 2005).

\section{Chlorine activation model}

The chlorine activation model describes the conversion of stratospheric chlorine reservoir species $\left(\mathrm{HCl}\right.$ and $\mathrm{ClONO}_{2}$, usually the dominating $\mathrm{Cl}_{\mathrm{y}}$ species) into active, ozone destroying forms of $\mathrm{ClO}_{\mathrm{x}}$ (see Appendix A) and back, depending on the abundance of PSCs and sunlight. An estimate of $\mathrm{Cl}_{\mathrm{y}}$ (see Appendix A) was derived as described in Newman et al. (2006). The approach by Newman et al. (2006) requires knowledge of the mean age-of-air and the width of the ageof-air spectrum. In this study, $\mathrm{Cl}_{\mathrm{y}}$ was calculated assuming a mean age-of-air of $5.5 \mathrm{yr}$ and an age-of-air spectrum width of $2.75 \mathrm{yr}$, which are the recommended values for the Antarctic in Newman et al. (2006).

The abundance of active, ozone destroying forms of chlorine in the stratosphere is approximated by $\mathrm{ClO}_{\mathrm{x}}$. Daytime measurements of $\mathrm{ClO}$ are a good proxy for the active forms of chlorine since a large fraction of $\mathrm{ClO}_{\mathrm{x}}$ resides in the form of $\mathrm{ClO}$ during day and as $\mathrm{Cl}_{2} \mathrm{O}_{2}$ during nighttime (Brasseur and Solomon, 2005). The time evolution of the abundance of $\mathrm{ClO}_{\mathrm{x}}$ can be described by integrating the terms expressing activation rates (conversion of chlorine reservoirs to active chlorine) and deactivation rates (reformation of chlorine reservoirs) over time. The time evolution of $\mathrm{ClO}_{\mathrm{x}}$ abundances depends on the total amount of available stratospheric chlorine $\left(\mathrm{Cl}_{\mathrm{y}}\right)$, the extent of PSCs within the polar vortex, solar illumination, and the deactivation of $\mathrm{ClO}_{\mathrm{x}}$ due to chemical reactions forming reservoir species.

The time rate of change of the vortex average $\mathrm{ClO}_{\mathrm{x}}$ (in parts per billion, $\mathrm{ppb}$ ) on a given pressure surface can be described by a first-order differential equation of the following form:

$$
\begin{aligned}
\frac{\mathrm{dClO}_{\mathrm{x}}}{\mathrm{d} t} & =\alpha \times\left(\mathrm{Cl}_{\mathrm{y}}-\mathrm{ClO}_{\mathrm{x}}\right) \times \mathrm{FAP} \times \mathrm{FAS} \\
& -\beta \times \mathrm{ClO}_{\mathrm{x}}(1-\mathrm{FAP}),
\end{aligned}
$$

where $\alpha$ and $\beta$ are fit coefficients derived by optimally fitting the equation to daytime $\mathrm{ClO}$ measurements. Acronyms for all physical quantities in the semi-empirical model are listed in Appendix A. The $\mathrm{Cl}_{\mathrm{y}}-\mathrm{ClO}_{\mathrm{x}}$ term represents chlorine still in reservoir forms, before its conversion to active chlorine. FAP is the fractional area of the vortex covered by PSCs. FAP is calculated using NCEP/NCAR temperature fields and a PSC formation threshold temperature of $195 \mathrm{~K}$. FAS is the fractional area of the vortex exposed to sunlight. When sunlight shines on the vortex it photolyses $\mathrm{Cl}_{2}, \mathrm{HOCl}$ and $\mathrm{BrCl}$ to $\mathrm{Cl}$ atoms, which rapidly react with ozone to form $\mathrm{ClO}$. In Fig. 1 FAP and FAS are shown from 1992 to 1997 at $70 \mathrm{hPa}$. FAS can decrease to very small values, but it never becomes zero.

$\mathrm{ClO}_{\mathrm{x}}$ becomes unavailable in the stratosphere through the following processes: (1) when $\mathrm{ClO}$ reacts with $\mathrm{NO}_{2}$ to form 


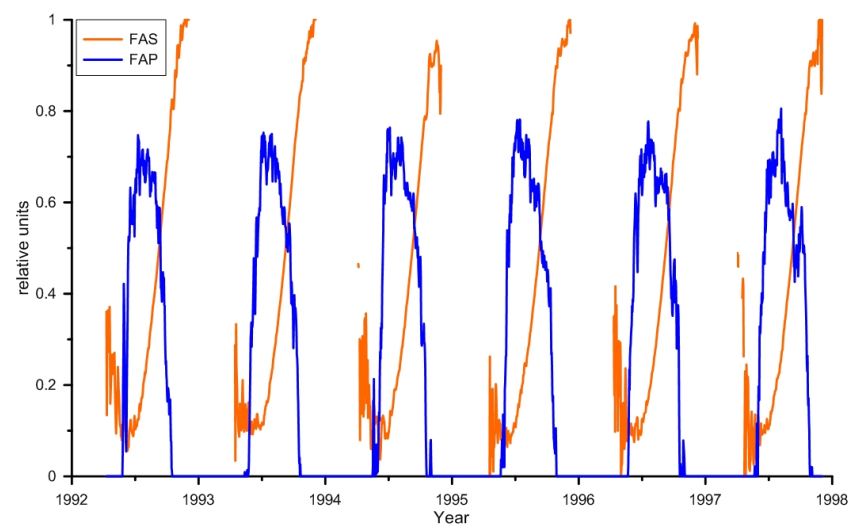

Fig. 1. Fractional vortex area covered by PSCs (FAP; blue) and fractional vortex area exposed to sunlight (FAS; orange) time series at $70 \mathrm{hPa}$ for $1992-1997$.

$\mathrm{ClONO}_{2}$, (2) when $\mathrm{ClO}$ reacts with $\mathrm{HO}_{2}$ to form $\mathrm{HOCl}$ and $\mathrm{O}_{2}$ (a minor reaction in the Antarctic), and (3) when $\mathrm{Cl}$ reacts with $\mathrm{CH}_{4}$ to form $\mathrm{HCl}$ and $\mathrm{CH}_{3}$. The first of these reactions depends on the availability of $\mathrm{NO}_{2}$ which is tied up in solid phase $\mathrm{HNO}_{3}$ within the PSCs or removed permanently from the lower stratosphere through denitrification. Deactivation of $\mathrm{ClO}_{\mathrm{x}}$ is parameterised by the second term in Eq. (1) where the decay of $\mathrm{ClO}_{\mathrm{x}}$ is dependent on FAP (proxy for PSCs).

Equation (1) is solved using a fourth-order Runge-Kutta algorithm. The equation is fitted to daytime measurements of $\mathrm{ClO}$ from the Microwave Limb Sounder (MLS) onboard the Upper Atmosphere Research Satellite (UARS) from 1992 to 1997 to derive a set of empirical fit coefficients. The fitting method used to find the optimal solution is a parameter space grid search technique. Version 5 MLS ClO measurements (Livesey et al., 2003) were averaged over $60-90^{\circ} \mathrm{S}$ equivalent latitude (as an approximation of vortex average $\mathrm{ClO}$ ), and only measurements taken near midday (i.e. with local solar zenith angle smaller than $88^{\circ}$ and local solar time between 11:00 and 14:00) were included (for details see Santee et al., 2003). The resulting fit coefficients are $\alpha=1.21$ and $\beta=0.76$. The fitting technique provides parameter values that best fit the data, but parameter uncertainties are not estimated with this technique.

In Fig. $2 \mathrm{ClO}$ observations and the semi-empirical model fit are shown. The model tracks the observations for activation and deactivation of $\mathrm{ClO}$ well; i.e. $60 \%$ of the variance in the $\mathrm{ClO}$ observations can be explained by the model. Because of the short data record, the ability of the model to track large inter-annual variability in chlorine activation is not immediately apparent. We are restricted to use UARS MLS ClO measurements for this study since measurements from the Aura satellite are only made in the later afternoon over Antarctica, and our assumption that $\mathrm{ClO}$ is a good proxy for $\mathrm{ClO}_{\mathrm{x}}$ does not apply in that case. Due to a known bias in the data (Livesey et al., 2003), the MLS ClO measurements show some deviation from zero before and after the period

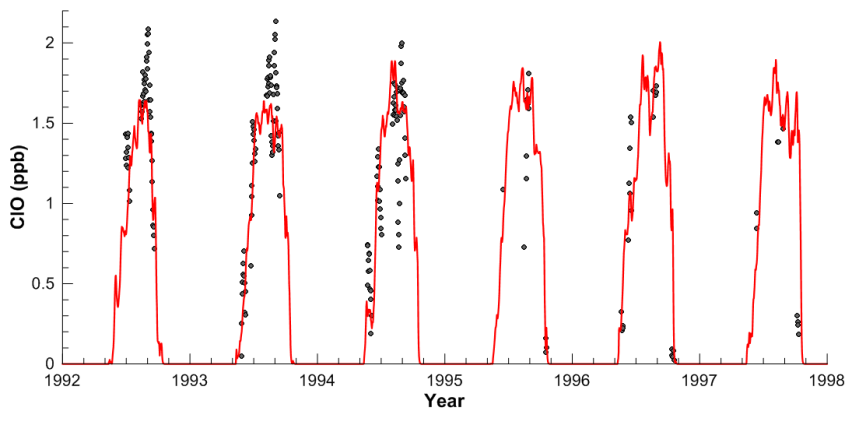

Fig. 2. UARS MLS daytime $\mathrm{ClO}$ measurements 20 May to 20 October (black dots) and semi-empirical model fit (red line) for 19921997. MLS observations are on the $520 \mathrm{~K}$ isentropic surface, and the model output is on the $50 \mathrm{hPa}$ pressure level.

of chlorine activation (not shown in Fig. 2). Therefore, the fitting of the model (Eq. 1) to the observations was restricted to 20 May to 20 October.

Equation (1) describes the activation and deactivation of $\mathrm{ClO}_{\mathrm{x}}$ on one pressure level. To derive the fit coefficients, $\mathrm{ClO}$ measurements at $520 \mathrm{~K}$ potential temperature were used for the fitting, and FAP and FAS were calculated at $50 \mathrm{hPa}$, which is the closest pressure level to the $520 \mathrm{~K}$ potential temperature surface. Using CCM output from two different CCMs (UMETRAC and NIWA-SOCOL) on 10 pressure levels, we found that, in the region of largest contribution (150$70 \mathrm{hPa}$ ), the fit coefficients do not vary significantly with altitude. Assuming no altitude dependence in the fit coefficients is therefore unlikely to introduce large uncertainties into our calculation of $\mathrm{ClO}_{\mathrm{x}}$ from FAP and FAS on any pressure level. Equation (1) is applied to FAP and FAS time series from 1979 to 2010 . To derive FAP and FAS only temperature and vortex edge information is needed, which in this study was obtained from NCEP/NCAR reanalyses. If this is simplified further by assuming an average vortex edge at $62^{\circ} \mathrm{S}$ (Bodeker et al., 2002), then only temperature fields and $\mathrm{Cl}_{\mathrm{y}}$ are required to derive $\mathrm{ClO}_{\mathrm{x}}$ time series.

\section{Ozone depletion model}

The second semi-empirical model describes the time rate of change of ozone mass deficit (OMD), a measure of springtime chemical ozone loss over Antarctica (Huck et al., 2007). OMD is a bulk measure of the size and depth of the ozone hole with respect to 1980 values, and it is one of the common metrics used to describe inter- and intra-annual variations in Antarctic ozone depletion (e.g. WMO, 2007, 2011). An improved definition of OMD (Huck et al., 2007) is used in this study, which is better able to capture the intra-seasonal evolution than the traditional definition (Uchino et al., 1999). 
The time rate of change of OMD is described using another first-order differential equation of the following form:

$$
\begin{aligned}
\frac{\mathrm{dOMD}}{\mathrm{d} t} & =\left[A \times \mathrm{sMAC}^{2}+B \times \mathrm{sMAC}\right] \times(1-S) \\
& -C \times \mathrm{OMD} \times F_{\mathrm{act}} \\
& -D \times \mathrm{OMD} \times \mathrm{WP} \times\left(1-\frac{\kappa}{\kappa_{\max }}\right) .
\end{aligned}
$$

The ozone model consists of three terms. Acronyms for all physical quantities in the semi-empirical model are listed in Appendix A. The first term relates the time rate of change of OMD to active chlorine. The amount of ozone that can be depleted has both a linear and a quadratic dependence on the amount of activated chlorine (Jiang et al., 1996). The sunlit mass of activated chlorine (sMAC) in Eq. (2) is an estimate of the total mass of activated chlorine in the atmospheric column relative to 1980 values and multiplied by FAS. The mass of activated chlorine (MAC) in the stratosphere is calculated for each layer:

$\mathrm{MAC}=\left(\mathrm{ClO}_{\mathrm{x}}-\mathrm{ClO}_{\mathrm{x} 1980}\right) \times \frac{M_{\mathrm{Cl}}}{M_{\mathrm{air}}} \times A \times \Delta p \times \frac{1}{g}$,

where $\mathrm{ClO}_{\mathrm{x}}$, obtained from Eq. (1), is the $\mathrm{ClO}_{\mathrm{x}}$ mixing ratio between two pressure levels. $\mathrm{ClO}_{\mathrm{x} 1980}$ is the background $\mathrm{ClO}_{\mathrm{x}}$ concentration corresponding to 1980 values. The time series for 1979-1981 were averaged to derive the concentration of active chlorine in 1980. The estimate for $\mathrm{ClO}_{\mathrm{x}}$ in $1980\left(\mathrm{ClO}_{\mathrm{x} 1980}\right)$ is calculated by fitting a six-term Fourier expansion to the 1979-1981 average $\mathrm{ClO}_{\mathrm{x}}$ time series on each pressure level. $M_{\mathrm{Cl}}$ is the molecular mass of chlorine ( $\left.35.45 \mathrm{~g} \mathrm{~mol}^{-1}\right)$, and $M_{\text {air }}$ is the molecular mass of dry air $\left(\sim 29 \mathrm{~g} \mathrm{~mol}^{-1}\right) . A$ is the area of the polar vortex in $\mathrm{m}^{2}$, $\Delta p$ the pressure difference for each layer in $\mathrm{Pa}$, and $g$ the gravitational acceleration $\left(9.81 \mathrm{~m} \mathrm{~s}^{-2}\right)$. Assuming a homogeneous distribution of $\mathrm{ClO}_{\mathrm{x}}$ over the polar vortex, MAC is multiplied by FAS to account for the fact that sunlight is needed for ozone destruction due to chlorine. Summation of MAC $\times$ FAS over all pressure levels $(200,150,100,70,50$, 30 , and $20 \mathrm{hPa}$ ) results in an estimate of the sunlit mass of activated chlorine (above $20 \mathrm{hPa}$ and below $200 \mathrm{hPa}$ the contribution to activated chlorine is close to zero). In Fig. 3 the contribution of each layer to sMAC is shown for 2000. It can be seen that the largest contributions come from pressures between 150 and $70 \mathrm{hPa}$. To account for saturation in ozone depletion (once ozone is depleted it cannot be depleted again), $S$ is set to $\mathrm{OMD} / \mathrm{OMD}_{150}$, where $\mathrm{OMD}_{150}$ is the value $\mathrm{OMD}$ would have if total ozone everywhere inside the vortex was $150 \mathrm{DU}$, which is approximately the vortex average value of total column ozone when all the lower stratospheric ozone is destroyed (Bodeker et al., 2002).

The second term in Eq. (2) relates the time rate of change in OMD to in situ production of ozone (through the Chapman cycle). This in situ production of ozone through Chapman chemistry is approximated via a parametrisation of the

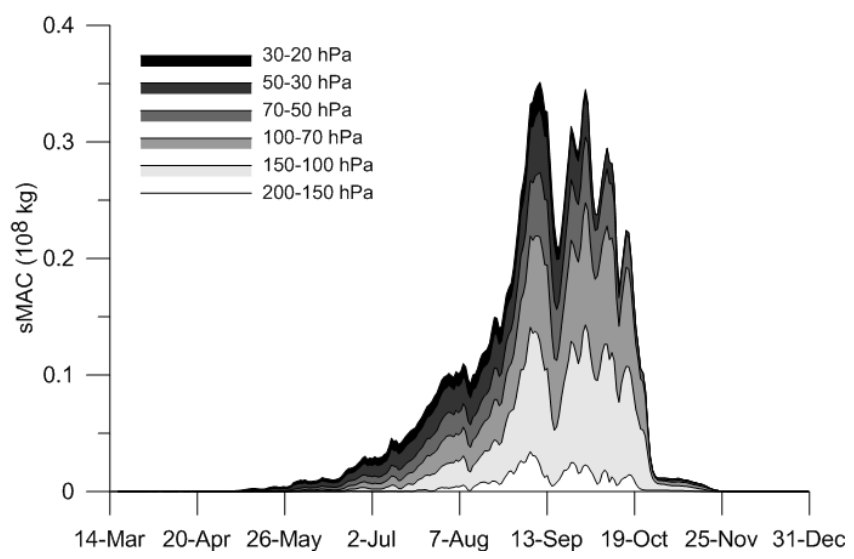

Fig. 3. Contribution from different atmospheric layers (as indicated in the legend) to the sunlit mass of activated chlorine for the year 2000. Largest contributions come from pressures between 150$70 \mathrm{hPa}$.

the actinic flux by taking the cosine of the solar zenith angle and the area within the polar vortex into account (Grooß et al., 2011). $F_{\text {act }}$ is a proxy of the actinic flux available to photolyse $\mathrm{O}_{2}$ and form $\mathrm{O}_{3} \cdot F_{\text {act }}$ is calculated as

$F_{\text {act }}=\cos (\mathrm{SZA}) \times e^{-1 / \cos (\mathrm{SZA})} \times A_{\mathrm{sun}}$,

where SZA is the solar zenith angle and $A_{\text {sun }}$ is the sunlit area inside the polar vortex.

The third term in Eq. (2) accounts for dynamical entrainment of ozone-rich air from lower latitudes. This process is described by taking the wave activity and vortex strength into account. WP is the total wave power at $60^{\circ} \mathrm{S}$ as calculated in Huck et al. (2005). $\kappa$ is the maximum of the meridional impermeability on each day, while $\kappa_{\max }$ is the maximum of the meridional impermeability for all equivalent latitudes and days in a given year (Bodeker et al., 2002). The $D$ term therefore quantifies the exchange of ozone between the interior and exterior of the vortex which is driven by wave mixing (hence the inclusion of the WP term) but blocked by the impermeability of the vortex (hence the inclusion of the $\kappa$-based term).

$A, B, C$ and $D$ in Eq. (2) are fit coefficients derived by optimally fitting the equation to OMD from observations. Equation (2) is also solved using a fourth-order Runge-Kutta algorithm. The equation is fitted to OMD calculated from the observational NIWA (National Institute of Water and Atmospheric research) combined total column ozone database (Bodeker et al., 2005) from 1990 to 2000. The fitting method used to find the optimal solution is the same parameter space grid search technique as used for the chlorine activation model (Eq. 1). The terms after each fit coefficient were normalised to vary between 0 and 1 , to make the fit coefficients comparable to each other. They result in $A=4.41 \times 10^{-7}$, $B=0.67, C=0.36$, and $D=1.43 \times 10^{-2}$. Similar to the fit coefficients in the chlorine model, no uncertainties are 
available with this fitting technique and the parameter values give the best fit to the data. The robustness of the fitting technique was tested by fitting to different periods and different number of years. The fit coefficients $A$ and $D$ are small compared to $B$ and $C$, which indicates that the linear dependence of ozone depletion on chlorine and the in situ production are the critical terms when describing the inter- and intra-annual variability of OMD. When the ozone depletion model is run from 1980 to 2010, the correlation coefficient between the model and observations is $R^{2}=0.97$ over the entire period.

To test the predictive capability of the semi-empirical models, the dynamical variability term ( $D$ term) was excluded and the input parameters FAS and FAP (now the only required parameters besides $\mathrm{Cl}_{\mathrm{y}}$ ) were calculated for 2000 to 2010 assuming a constant vortex edge at $62^{\circ} \mathrm{S}$ (see also Huck et al., 2007). In Fig. 4 OMD observations, the full model and the simplified model predictions are shown for 1980 to 2010. The model tracks the observations for the seasonal evolution of ozone depletion. The year-to-year variability of the Antarctic ozone hole is also well represented, in particular for the anomalous years 1988, 2002 and 2004. The simulation using the simplified version of the model reproduces intra- and inter-annual variability of OMD. The fact that both model versions track the observations between 2000 and 2010 (including two of the anomalous years), which were not used to derive the fit parameters, demonstrates the predictive capability of such semi-empirical models.

\section{Discussion and conclusion}

Fit coefficients such as those in the two semi-empirical models described above can be used to determine key sensitivities in the stratosphere. For example, the fit coefficients of the OMD model (Eq. 2) indicate a linear dependence between ozone depletion and chlorine in the Antarctic stratosphere in agreement with the findings of Harris et al. (2010).

Activation of chlorine in the polar stratosphere in the future will be linked to climate change: future increases in atmospheric concentrations of GHGs will cool the stratosphere which, together with possible increases in water vapour (WMO, 2011), will promote the formation of PSCs. In contrast, changes in surface climate will likely increase wave activity emanating from the troposphere into the stratosphere, causing warming in the polar stratosphere (Austin and Wilson, 2006). The future interplay between these factors is unknown (WMO, 2011). Fit coefficients of semi-empirical models such as those described above can be used to investigate aspects of the interaction between climate change and Antarctic ozone depletion. For example, for a range of different GHG emissions scenarios atmosphere-ocean general circulation models could be used to generate different stratospheric temperature fields. With the fit coefficients of the semi-empirical models, different projections of ozone depletion can be generated.

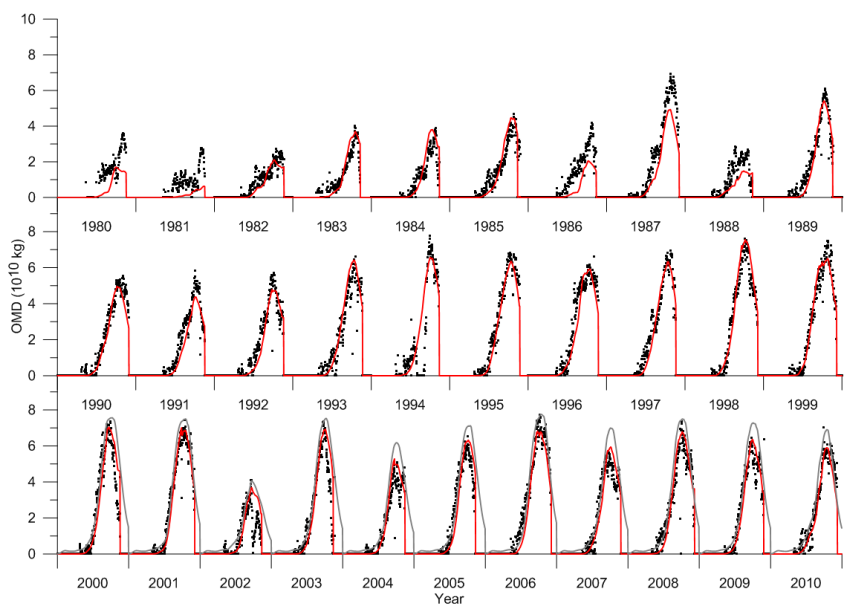

Fig. 4. OMD observations (black dots), OMD model (red line: full model, Eq. (2); grey line: simplified model). Note that the model is fitted to the OMD measurements from 1990 to 2000 and is forced to zero at the end of each season. The simplified model projections are only shown for 2000 to 2010 .

It was shown that a further simplification of the equations by excluding the dynamical variability term and by replacing the actual dynamical vortex edge with the average location of the vortex edge of $62^{\circ} \mathrm{S}$ provides models with the ability to project the development of Antarctic ozone into the future. As long as temperature projections and $\mathrm{Cl}_{\mathrm{y}}$ estimates are available, these models can provide an estimate of the future evolution of Antarctic ozone. Since these models are fast and inexpensive to run, they can, for example, be used to produce an ensemble of ozone projections considering a range of GHG emissions scenarios.

There are limitations to these equations, which is why this study should be considered as proof-of-concept rather than a finished product. As they stand, these semi-empirical models cannot be applied outside the Antarctic vortex. Finer differentiation between physical and chemical processes might be necessary for more detailed studies of key atmospheric sensitivities of ozone depletion and climate change. In this proof-of-concept paper, a very simplified version of a semiempirical model for stratospheric ozone depletion was introduced. These semi-empirical models which only consider bulk quantities do not appear to be very sensitive to changes in atmospheric dynamics. Due to the expected increase in the importance of dynamical processes, it might be necessary to model single levels in the atmosphere in the future. 


\section{Appendix A}

\section{List of acronyms}

$\mathrm{ClO}_{\mathrm{x}}$ active chlorine (here: $\mathrm{ClO}_{\mathrm{x}}=2 \times \mathrm{Cl}_{2} \mathrm{O}_{2}+$ $\mathrm{ClO})$

$\mathrm{Cl}_{\mathrm{y}} \quad$ total chlorine

$\left(\mathrm{Cl}_{\mathrm{y}}=\mathrm{HCl}+\mathrm{ClONO}_{2}+\mathrm{HOCl}+2 \times \mathrm{Cl}_{2}+\right.$ $\left.2 \times \mathrm{Cl}_{2} \mathrm{O}_{2}+\mathrm{ClO}+\mathrm{Cl}\right)$

FAP fractional vortex area covered by PSCs

FAS fractional vortex area exposed to sunlight

MAC mass of activated chlorine

sMAC sunlit mass of activated chlorine

S saturation term

$F_{\text {act }} \quad$ proxy for actinic flux

WP wave power

$\kappa \quad$ maximum meridional impermeability on each day

$\kappa_{\max } \quad$ maximum meridional impermeability per year

Acknowledgements. This work was supported by the DFG (Deutsche Forschungsgemeinschaft) and by the Marsden Fund Council from Government funding, administered by the Royal Society of New Zealand. NCEP/NCAR reanalyses were provided by the NOAA-CIRES Climate Diagnostics Center, Boulder, Colorado, USA, from their Web site at http://www.cdc.noaa.gov/. We would like to thank Michelle Santee for providing the MLS data and for detailed comments and suggestions on the manuscript.

Edited by: M. Dameris

\section{References}

Austin, J. and Wilson, R. J.: Ensemble simulations of the decline and recovery of stratospheric ozone, J. Geophys. Res., 111, D16314, doi:10.1029/2005JD006907, 2006.

Bodeker, G. E., Struthers, H., and Connor, B. J.: Dynamical containment of Antarctic ozone depletion, Geophys. Res. Lett., 29, doi:10.1029/2001GL014206, 2002.

Bodeker, G. E., Shiona, H., and Eskes, H.: Indicators of Antarctic ozone depletion, Atmos. Chem. Phys., 5, 2603-2615, doi:10.5194/acp-5-2603-2005, 2005.

Brasseur, G. and Solomon, S.: Aeronomy of the Middle Atmosphere, Springer, 2005.

Cariolle, D. and Teyssèdre, H.: A revised linear ozone photochemistry parameterization for use in transport and general circulation models: multi-annual simulations, Atmos. Chem. Phys., 7, 21832196, doi:10.5194/acp-7-2183-2007, 2007.

Chapman, S.: A theory of upper atmospheric ozone, Mem. Roy. Soc., 3, 103-109, 1930.

Charlton-Perez, A. J., Hawkins, E., Eyring, V., Cionni, I., Bodeker, G. E., Kinnison, D. E., Akiyoshi, H., Frith, S. M., Garcia, R., Gettelman, A., Lamarque, J. F., Nakamura, T., Pawson, S., Yamashita, Y., Bekki, S., Braesicke, P., Chipperfield, M. P.,
Dhomse, S., Marchand, M., Mancini, E., Morgenstern, O., Pitari, G., Plummer, D., Pyle, J. A., Rozanov, E., Scinocca, J., Shibata, K., Shepherd, T. G., Tian, W., and Waugh, D. W.: The potential to narrow uncertainty in projections of stratospheric ozone over the 21st century, Atmos. Chem. Phys., 10, 94739486, doi:10.5194/acp-10-9473-2010, 2010.

Chipperfield, M. P. and Pyle, J. A.: Model sensitivity studies of Arctic ozone depletion, J. Geophys. Res.-Atmos., 103, 2838928403, 1998.

Grooß, J.-U., Brautzsch, K., Pommrich, R., Solomon, S., and Müller, R.: Stratospheric ozone chemistry in the Antarctic: what determines the lowest ozone values reached and their recovery?, Atmos. Chem. Phys., 11, 12217-12226, doi:10.5194/acp11-12217-2011, 2011.

Harris, N. R. P., Lehmann, R., Rex, M., and von der Gathen, P.: A closer look at Arctic ozone loss and polar stratospheric clouds, Atmos. Chem. Phys., 10, 8499-8510, doi:10.5194/acp-10-84992010, 2010.

Hsu, J. and Prather, M. J.: Stratospheric variability and tropospheric ozone, J. Geophys. Res.-Atmos., 114, doi:10.1029/2008JD010942, 2009.

Huck, P. E., McDonald, A. J., Bodeker, G. E., and Struthers, H.: Interannual variability in Antarctic ozone depletion controlled by planetary waves and polar temperature, Geophys. Res. Lett., 32, L13819, doi:10.1029/2005GL022943, 2005.

Huck, P., Tilmes, S., Bodeker, G., Randel, W., McDonald, A., and Nakajima, H.: An improved measure of ozone depletion in the Antarctic stratosphere, J. Geophys. Res., 112, doi:10.1029/2006JD007860, 2007.

Jiang, Y. B., Yung, Y. L., and Zurek, R. W.: Decadal evolution of the Antarctic ozone hole, J. Geophys. Res.-Atmos., 101, 8985-8999, 1996.

Livesey, N. J., Read, W. G., Froidevaux, L., Waters, J. W., Santee, M. L., Pumphrey, H. C., Wu, D. L., and Jarnot, R. F.: The UARS Microwave Limb Sounder version 5 data set: Theory, characterization, and validation, J. Geophys. Res., 108, 4378, doi:10.1029/2002JD002273, 2003.

McLinden, C., Olsen, S., Hannegan, B., Wild, O., and Prather, M.: Stratospheric ozone in 3-D models: a simple chemistry and the cross-tropopause flux, J. Geophys. Res., 105, 14653-14665, 2000 .

Newman, P. A., Nash, E. R., Kawa, S. R., Montzka, S. A., and Schauffler, S. M.: When will the Antarctic ozone hole recover?, Geophys. Res. Lett., 33, doi:10.1029/2005GL025232, 2006.

Santee, M. L., Manney, G. L., Waters, J. W., and Livesey, N. J.: Variations and climatology of $\mathrm{ClO}$ in the polar lower stratosphere from UARS Microwave Limb Sounder measurements, J. Geophys. Res.-Atmos., 108, doi:10.1029/2002JD003335, 2003.

Sinnhuber, B.-M., Sheode, N., Sinnhuber, M., Chipperfield, M. P., and Feng, W.: The contribution of anthropogenic bromine emissions to past stratospheric ozone trends: a modelling study, Atmos. Chem. Phys., 9, 2863-2871, doi:10.5194/acp-9-2863-2009, 2009.

Solomon, S.: Stratospheric ozone depletion: A review of concepts and history, Rev. Geophys., 37, 275-316, doi:10.1029/1999RG900008, 1999.

SPARC CCMVal: SPARC Report on the Evaluation of ChemistryClimate Models, WCRP-132, SPARC Report No. 5, 2010. 
Uchino, O., Bojkov, R. D., Balis, D. S., Akagi, K., Hayashi, M., and Kajihara, R.: Essential characteristics of the Antarctic-spring ozone decline: Update to 1998, Geophys. Res. Lett., 26, 13771380, 1999.

von Hobe, M., Grooß, J.-U., Müller, R., Hrechanyy, S., Winkler, U., and Stroh, F.: A re-evaluation of the $\mathrm{ClO} / \mathrm{Cl}_{2} \mathrm{O}_{2}$ equilibrium constant based on stratospheric in-situ observations, Atmos. Chem. Phys., 5, 693-702, doi:10.5194/acp-5-693-2005, 2005.

Waugh, D. W. and Randel, W. J.: Climatology of Arctic and Antarctic polar vortices using elliptical diagnostics, J. Atmos. Sci., 56, 1594-1613, 1999.
WMO: Scientific Assessment of ozone depletion: 2002, World Meteorological Organisation Global Ozone Research and Monitoring Project Report No. 47, 2003.

WMO: Scientific Assessment of Ozone Depletion: 2006, World Meteorological Organization Global Ozone Research and Monitoring Project Report No. 50, Geneva, 2007.

WMO: Scientific Assessment of Ozone Depletion: 2010, World Meteorological Organization Global Ozone Research and Monitoring Project Report No. 52, Geneva, 2011. 